\title{
Teor crítico de enxofre no solo para o estabelecimento de clones de erva-mate no Sul do Brasil
}

\author{
Critical level of available sulphur in the soil during establishment of clones of yerba mate at Southern Brazil
}

\section{Djalma Eugênio Schmitt ${ }^{1 *}$, Rodrigo Balen Vendrusculo ${ }^{1}$, Luciano Colpo Gatiboni ${ }^{1}$, Delmar Santin ${ }^{2}$, Ivar Wendling ${ }^{3}$, Daniel João Dall'Orsoletta ${ }^{1}$ \& Flávia Denise Coldebella ${ }^{1}$}

\author{
${ }^{1}$ Universidade do Estado de Santa Catarina, Lages, SC, Brasil. *Autor para correspondência: djalma.schmitt@gmail.com. \\ ${ }^{2}$ Cambona Consultoria e Tecnologia Agroendustrial, Santa Terezinha de Itaipu, PR, Brasil. \\ ${ }^{3}$ Empresa Brasileira de Pesquisa Agropecuária, Colombo, PR, Brasil.
}

\begin{abstract}
RESUMO
O cultivo da erva-mate (Ilex paraguariensis St. Hil.) apresenta grande importância econômica na região Sul do Brasil. Contudo, a necessidade de fertilização no estabelecimento de plantios de erva-mate ainda é pouco conhecida. $O$ trabalho objetivou avaliar a adubação sulfatada no crescimento inicial de dois clones de erva-mate em um Cambissolo Húmico. O experimento foi implantado em Itaiópolis, SC, testando quatro doses de enxofre (S) $\left(0 ; 1,2 ; 2,4\right.$ e 3,6 $\mathrm{kg}$ de S-SO $\left.4 \mathrm{ha}^{-1}\right)$ em dois clones femininos de erva-mate (F1 e F2). Avaliou-se a massa verde e a exportação de nutrientes pelas folhas, galhos finos $(\leq 7 \mathrm{~mm})$, galhos grossos $(>7 \mathrm{~mm}$ ) e erva-mate comercial (folhas + galhos finos) e massa total. O S-SO 4 foi avaliado na camada de $0-20 \mathrm{~cm}$ do solo 24 meses após a aplicação dos tratamentos e plantio das mudas. A produtividade de galho fino e a massa total foram influenciadas pela dose de $S$, independentemente do clone, indicando a exigência do nutriente para aumentar o rendimento de massa verde. Ainda, o clone F2 apresentou maior produção de galho grosso em função da dose de S. Assim, sugere-se o teor mínimo de $10 \mathrm{mg} \mathrm{dm}^{-3} \mathrm{~S}_{-} \mathrm{SO}_{4}$ no solo para um adequado estabelecimento de clones de erva-mate.
\end{abstract}

PALAVRAS-CHAVE: adubação sulfatada, sulfato, Ilex paraguariensis.

\begin{abstract}
The cultivation of yerba mate (Ilex paraguariensis St. Hil.) has great economic importance in the Southern of Brazil. However, the fertilization requirements in the establishment of yerba mate plantations is still unknown. The objective of this work was to evaluate the needs of sulfate fertilization on the initial growth of two clones of yerba mate in a Humic Cambisol. An experiment was carried out in Itaiópolis, SC and four doses of $\mathrm{S}\left(0.0 ; 1.2 ; 2.4\right.$ and $3.6 \mathrm{~kg} \mathrm{ha}^{-1}$ of S-SO $\left.{ }_{4}{ }^{2-}\right)$ and two clones (F1 and F2) were tested. The green mass and the export of nutrients were evaluated: leafs, fine twigs, thick twigs and commercial yerba mate (leaf + fine twigs), and total mass. Soil available S-SO 4 was evaluated in the $0-20 \mathrm{~cm}$ soil layer 24 months after planting. The production of thick twigs increased with application of $S$, for clone F2. However, the yield of fine twig and total mass were influenced by the dose of $\mathrm{S}$, independent of the clone. Thus, there was a positive response from the application of sulfur to clone F2, indicating that it is demanding on the nutrient, increasing the yield of green mass and the levels of $\mathrm{S}_{-} \mathrm{SO}_{4}$ in the soil.
\end{abstract}

KEYWORDS: sulfur fertilization, sulphate, Ilex paraguariensis.

\section{INTRODUÇÃO}

A erva-mate (llex paraguariensis St. Hil.) é uma das espécies arbóreas nativas de maior importância econômica na região Sul do Brasil (SANTOS et al. 2004), sendo as folhas desidratadas comercializadas e consumidas principalmente na forma de chá. No Brasil, geralmente o cultivo de erva-mate é realizado em solos ácidos e de baixa fertilidade natural (SANTIN et al. 2013a, OLIVA et al. 2014). O produto colhido é composto predominantemente por folhas, galhos finos, botões florais e sementes, todos considerados órgãos que concentram grande quantidade de nutrientes, dentre eles, o enxofre (S) (BRUN et al. 2014). Inicialmente, parte do $S$ exportado via planta pode ser reposto naturalmente pelo solo, através do intemperismo de minerais primários, e também pelas deposições atmosféricas, decomposição de resíduos e adição de defensivos ou fertilizantes (ALVAREZ et al. 2007); mas, principalmente, pela mineralização da 
matéria orgânica do solo, uma vez que cerca de $90 \%$ do $S$ do solo estão presentes nesse compartimento (KLIEMANN \& MALAVOLTA 1993). Assim, a disponibilidade de $S$ às plantas está relacionada com a taxa de mineralização de S orgânico (KLIEMANN \& MALAVOLTA 1993).

No entanto, o $\mathrm{S}$ proveniente dessas fontes pode ser insuficiente para o adequado crescimento das plantas, já que, por exemplo, o processo de intemperismo dos minerais primários é lento, as deposições atmosféricas dependem da proximidade dos grandes centros urbanos e a mineralização de matéria orgânica é dependente de outros fatores de regulação. O aparecimento de sintomas de deficiência de $S$ nas plantas cultivadas vem crescendo nas últimas décadas, devido ao aumento no uso de fertilizantes concentrados livres de $S$, às colheitas intensivas, à remoção completa dos resíduos da área, à lixiviação e à erosão (MELO et al. 2011). Para evitar esse problema, recomendam-se adubações com fertilizantes sulfatados, elevando os teores de $S$ próximo às raízes de forma a aumentar a assimilação para os órgãos internos (ALVAREZ et al. 2007). Essa prática tende a elevar a produtividade das plantas em solos com teores abaixo do nível de suficiência (CQFS-RS/SC 2016), visto que o $S$ é essencial na formação de aminoácidos e vitaminas, além de ter papel fundamental na formação de clorofila (TAIZ et al. 2015). Aliado a isso, periodicamente ocorre o corte de galhos e ramos que acabam exportando nutrientes, dentre eles 0 S, que precisa ser reposto pela adubação (CQFS-RS/SC 2016).

O teor crítico de $\mathrm{S}$ no solo, considerado pela CQFS-RS/SC (2016), é de 5,0 $\mathrm{mg} \mathrm{dm}^{-3}$ para culturas menos exigentes, como a erva-mate, e $10 \mathrm{mg} \mathrm{dm}^{-3}$ para as culturas mais exigentes. No entanto, para o caso da erva-mate, esse teor crítico foi estabelecido empiricamente por similaridade da espécie com outras culturas florestais, não tendo sido realizados experimentos de calibração para tal. Portanto, estudos mais aprofundados devem ser desenvolvidos no intuito de determinar a exigência nutricional da espécie na fase inicial de estabelecimento de mudas a campo, importante para o sucesso do futuro plantio e, consequentemente, do ganho na produtividade (SANTIN et al. 2008).

As plantas de erva-mate podem apresentar resposta diferenciada à aplicação de nutrientes de acordo com o material genético (XAVIER et al. 2009, XAVIER \& SILVA 2010, BENIN et al. 2013). Assim, a resposta à aplicação de $S$ pode ser influenciada pelo material vegetal, como o clone no caso da erva-mate. Todavia, são escassos os trabalhos que avaliem a adubação em erva-mate a campo, especialmente com S. Assim, nossas hipóteses são: (I) a aplicação de enxofre melhora o estabelecimento de mudas clonais de ervamate, incrementando a absorção desses nutrientes e também a produção da erva-mate; (II) a resposta à adubação sulfatada é dependente do clone cultivado.

O objetivo do trabalho foi avaliar a resposta de clones de erva-mate à adubação sulfatada em fase de estabelecimento da cultura a campo.

\section{MATERIAL E MÉTODOS}

O estudo foi realizado de 2013 a 2015, no município de Itaiópolis $\left(26^{\circ} 25^{\prime} 44^{\prime \prime S}\right.$ e $\left.49^{\circ} 55^{\prime} 45^{\prime \prime} \mathrm{W}\right)$, estado de Santa Catarina. A região se caracteriza por um clima temperado mesotérmico tipo (Cfb) segundo a classificação de Köppen. Possui temperatura média no mês mais frio abaixo de $18{ }^{\circ} \mathrm{C}$ (mesotérmico), verões frescos, temperatura média no mês mais quente abaixo de $22^{\circ} \mathrm{C}$ e sem estação seca definida (EPAGRI 2002).

O solo é classificado como Cambissolo húmico (CH) (EMBRAPA 2013), apresentando pH em água 1:1 de 4,9; teores de $\mathrm{Ca}^{2+}, \mathrm{Mg}^{2+}$ e $\mathrm{Al}^{3+}$ de 2,4, 0,5 e 4,7 $\mathrm{cmolc}_{\mathrm{cm}}^{3}$, respectivamente; $\mathrm{H}+\mathrm{Al}$ e CTC $\mathrm{pH}$ 7,0 de 13,7 e $17 \mathrm{cmol}_{\mathrm{c}} \mathrm{dm}^{3}$; teor de argila e de carbono orgânico de $510 \mathrm{~g} \mathrm{~kg}^{-1}$ e $24 \mathrm{~g} \mathrm{dm}^{3} ; \mathrm{P}, \mathrm{K}$ e S-SO ${ }_{4}^{2-}$ de 8,2 , 204 e $8,0 \mathrm{mg} \mathrm{dm}^{3}$, respectivamente. Antes da implantação do experimento, o solo era cultivado com cultura florestal de Pinus spp.

No início, aplicaram-se superficialmente $3,5 \mathrm{Mg}^{\text {ha-1 }}$ de calcário dolomítico ( $\mathrm{CaO}$ e MgO, 31,6 e $20,3 \%$, respectivamente) para elevar os teores de $\mathrm{Ca}$ e Mg no solo, conforme recomendação de SANTIN et al. (2013b). Em seguida, o solo da linha de plantio foi escarificado a uma profundidade de $40 \mathrm{~cm}$ usando escarificador de uma haste. O delineamento experimental utilizado foi o de blocos ao acaso com parcelas subdivididas e quatro repetições. Cada unidade experimental foi composta por 12 plantas de erva-mate, plantadas em espaçamento de 2,0 × 2,5 m, totalizando 2.000 plantas por ha ${ }^{-1}$. Nas parcelas foram aplicadas doses de $S\left(0 ; 1,2 ; 2,4\right.$ e 3,6 $\mathrm{g}_{\text {planta-1 }}{ }^{-1}$, equivalentes a $0 ; 3,6 ; 6,4$ e 10,8 $\mathrm{kg}$ ha-1 de sulfato, e, nas subparcelas, foram testados dois clones femininos de erva-mate ( $F 1$ e F2). A adubação sulfatada foi fracionada e aplicada em quatro épocas, sendo $25 \%$ da dose aplicados na cova de plantio e o restante em três aplicações superficiais de igual dose (adubação de crescimento), aos 4, 12 e 16 meses após o plantio das mudas. A adubação de crescimento com N, $\mathrm{P}_{2} \mathrm{O}_{5}, \mathrm{~K}_{2} \mathrm{O}$ e $\mathrm{S}$ foi aplicada superficialmente na área de projeção da copa sem incorporação, mantendo uma distância de $20 \mathrm{~cm}$ de raio da planta sem aplicar 
fertilizante, para evitar efeito salino. A fonte de $S$ utilizada foi o sulfato de potássio ( $18 \%$ de $S$ e $50 \%$ de $\left.\mathrm{K}_{2} \mathrm{O}\right)$.

O plantio ocorreu em setembro de 2013 e, juntamente com a dose de $\mathrm{S}$, cada tratamento recebeu a aplicação de 3,8; 2,5 e 2,5 g planta- ${ }^{-1}$ de $\mathrm{N}, \mathrm{P}_{2} \mathrm{O}_{5}$ e $\mathrm{K}_{2} \mathrm{O}$, respectivamente, nas formas de ureia (45\% de $\mathrm{N}$ ), superfosfato triplo $\left(42 \%\right.$ de $\left.\mathrm{P}_{2} \mathrm{O}_{5}\right)$ e cloreto de potássio $\left(60 \%\right.$ de $\left.\mathrm{K}_{2} \mathrm{O}\right)$. Para adubação de crescimento utilizaram-se as doses 3,8, 2,5 e 2,2 $\mathrm{g}_{\text {planta- }}^{-1}$ de N, $\mathrm{P}_{2} \mathrm{O}_{5}$ e $\mathrm{K}_{2} \mathrm{O}$, conforme recomendado por SANTIN et al. (2013a). Como a fonte sulfatada continha $\mathrm{K}$ em sua fórmula, adicionaram-se doses de cloreto de potássio, variável para cada dose de $\mathrm{S}$, suficientes para que ao final todas as plantas recebessem a mesma dose de $\mathrm{K}_{2} \mathrm{O}$.

No plantio, em setembro de 2013 , todos os adubos foram homogeneizados a $15 \mathrm{dm}^{-3}$ de solo. Para isso, retirava-se o solo da cova e aferia-se seu volume em um balde; na sequência, o solo e os adubos eram acondicionados em um saco plástico, onde eram homogeneizados. Ao final, o solo já adubado retornava à cova. Os clones foram plantados duas semanas após adubar o solo da cova. O povoamento não foi irrigado após o plantio.

As mudas dos clones femininos F1 e F2 foram selecionadas pela Embrapa Florestas e a Empresa Baldo S/A de um jardim clonal de alta produtividade, as quais fazem porte de um programa de clonagem da erva-mate. Ambas as matrizes são oriundas de São Mateus do Sul (PR) e foram selecionadas por apresentarem matéria-prima que dá origem a uma bebida (chimarrão) suave. A propagação das mudas foi realizada por miniestaquia a partir de clones resgatados via enxertia e estaquia, conforme WENDLING et al. (2007). Após as mudas passarem pelas fases de enraizamento, aclimatação, rustificação e atingirem altura média de $12 \mathrm{~cm}$, foram transplantadas a campo. Após o plantio, as mudas receberam uma proteção de laminado de $50 \mathrm{~cm}$ de altura, fixada na orientação oeste a aproximadamente $15 \mathrm{~cm}$ da muda para atenuar o sol da tarde. As áreas foram sempre mantidas com cobertura verde, no inverno com aveia preta (Avena strigosa) e no verão com sorgo forrageiro (Sorghum bicolor); no final do ciclo de cada cobertura foi efetuada a roçada na área. Três meses após o plantio efetuou-se coroamento, com capina manual em área de aproximadamente $30 \mathrm{~cm}$ de raio da muda. A avaliação da sobrevivência foi realizada aos 120 dias após o plantio, sendo a mesma de $97 \%$.

Após 24 meses do plantio foi realizada a primeira colheita, com poda drástica, que consistiu no corte do tronco a uma altura entre 10 a $15 \mathrm{~cm}$ acima do solo, permanecendo somente os brotos basais laterais. Esse tipo de poda induz o surgimento de vários brotos basais que favorecem a futura formação da copa. No momento da colheita, a biomassa colhida foi separada e pesada por parcela de cada tratamento em erva-mate comercial ( $E C O M$ = folha mais galho fino com diâmetro máximo de $7 \mathrm{~mm}$ ) e galho grosso $(G G=$ diâmetro maior que $7 \mathrm{~mm})$. Coletou-se uma amostra representativa de ECOM $( \pm 500 \mathrm{~g})$, retirada do terço médio da altura da copa, que foi separada em folha (FO) e galho fino (GF).

No momento da coleta, todas as amostras foram pesadas no campo com balança eletrônica de precisão de $\pm 5 \mathrm{~g}$ evitando perda de água da biomassa. No laboratório, as amostras das diferentes porções da planta foram secas em estufa a $65 \stackrel{\circ}{\circ}$ até peso constante e, após determinada a massa seca, foram trituradas em moinho tipo Wiley. A abertura do tecido para a avaliação do teor de $S$ foi realizada por digestão nitroperclórica, sendo determinado por turbidimetria (ALVAREZ et al. 2001).

No momento da colheita, fez-se a coleta de solo com trado calador na camada de $0-20 \mathrm{~cm}$ de profundidade na linha de plantio, coletada na área de projeção da copa da planta onde houve adubação. $O$ solo foi seco em estufa a $60{ }^{\circ} \mathrm{C}$, moído e tamisado em peneira de $2 \mathrm{~mm}$, a fim de se analisar o teor de sulfato disponível, o qual foi extraído por solução de fosfato monocálcico $\left(\mathrm{Ca}\left(\mathrm{H}_{2} \mathrm{PO}_{4}\right)^{2}\right)$ de $500 \mathrm{mg} \mathrm{L}^{-1}$ de $\mathrm{P}$ em ácido acético $\left(\mathrm{CH}^{3} \mathrm{COOH}\right) 2 \mathrm{~mol} \mathrm{~L}-1$ (ALVAREZ et al. 2001).

Os dados de massa das diferentes partes das plantas, a quantidade de $S$ exportado e os teores de $S$ $\mathrm{SO}_{4}^{2-}$ no solo foram submetidos à análise de variância (Anova). Quando o efeito para clones foi significativo, foi realizado teste de comparação de médias (Tukey, $p<0,05$ ) e, quando o efeito das doses de $S$ foi significativo, ajustaram-se as equações de regressão polinomial, optando-se pelo modelo significativo de mais alto grau utilizando o software SISVAR (FERREIRA 2008).

\section{RESULTADOS E DISCUSSÃO}

Houve pouca variação no teor de massa seca entre os tratamentos (dados não apresentados) e, como a erva-mate é comercializada por massa verde, optou-se por apresentar os dados desta forma. Pelos dados apresentados na Tabela 1, é possível observar que houve resposta à aplicação de $\mathrm{S}$ no solo para a produção de massa verde de galho fino (GF), massa verde total, exportação de $S$ pelas folhas (FO), erva-

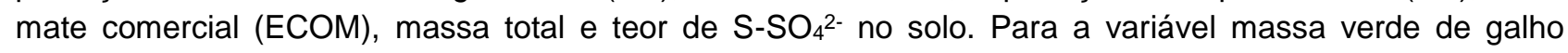


grosso (GG) houve interação $(p=0,0482)$ entre dose e clone (Tabela 1). Já a exportação de $S$ de $G G$ foi influenciada somente pelo clone.

Tabela 1. Valor de $\mathrm{p}$ das variáveis analisadas após a aplicação de doses de $\mathrm{S}$ para dois clones de ervamate em um Cambissolo Húmico, após 24 meses de cultivo.

Table 1. Summary of the statistical analysis of the variables analyzed after the application of rates of $S$ in two clones of yerba mate in a Humic Cambisol after 24 months of cultivation.

\begin{tabular}{|c|c|c|c|c|c|c|c|c|c|c|c|}
\hline \multirow{2}{*}{$\begin{array}{l}\text { Fontes de } \\
\text { Variação }\end{array}$} & \multicolumn{5}{|c|}{--- Massa verde --------- } & \multicolumn{5}{|c|}{-- Exportação de S --------- } & \multirow{2}{*}{$\begin{array}{c}\text { Solo } \\
\text { S }\end{array}$} \\
\hline & FO & GF & GG & ECOM & Total & FO & GF & GG & ECOM & Total & \\
\hline Dose & 0,063 & 0,046 & 0,036 & 0,051 & 0,028 & 0,009 & 0,785 & 0,127 & 0,021 & 3 & 38 \\
\hline Clone & 0,575 & 0,831 & 0,409 & 0,674 & 0,958 & 0,364 & 0,616 & 0,025 & 0,389 & 0,157 & \\
\hline Dose ${ }^{*}$ Clone & 0,111 & 0,666 & 0,048 & 0,092 & 0,053 & 0,394 & 0,346 & 0,680 & 0,378 & 0,363 & \\
\hline
\end{tabular}

$\mathrm{FO}=$ folha; $\mathrm{GF}$ = galho fino; $\mathrm{GG}=$ galho grosso; $\mathrm{ECOM}=$ Erva comercial (Fo + GF); Total = massa total.S-SO4.

A produção de $\mathrm{GG}$ aumentou com aplicação de $\mathrm{S}$, para o clone $\mathrm{F} 2$, com resposta máxima estimada para a dose de 2,07 $\mathrm{kg} \mathrm{ha}^{-1}$ de S (Figura 1a). Essa dose representou uma produção de 0,56 $\mathrm{Mg} \mathrm{ha}^{-1}$ de GG. Já a produção de $G G$ para o clone $F 1$ não foi influenciada pela dose de $S$, com produtividade média de 0,41 $\mathrm{Mg} \mathrm{ha}^{-1}$. A produtividade de GF e a massa total foram influenciadas pela dose de $\mathrm{S}$, independentemente do clone (Figura 1b). Houve efeito linear da aplicação de S para a variável GF (Figura 1b), com incremento de $16 \mathrm{~kg}$ de massa verde para cada $\mathrm{kg}$ de $\mathrm{S}$ aplicado ao solo. Já para massa total, houve resposta quadrática, sendo a produção máxima estimada de $1,56 \mathrm{Mg} \mathrm{ha}^{-1}$ alcançada com a dose de $2,5 \mathrm{~kg} \mathrm{ha}^{-1}$ de $\mathrm{S}$ aplicado ao solo. No entanto, mesmo a menor dose de $S$ aplicada $\left(1,2 \mathrm{~kg} \mathrm{ha}^{-1}\right)$ apresentou rendimento de $90 \%$ do máximo estimado, mostrando que a aplicação de uma pequena quantidade de $S$ já é suficiente para maximizar a produtividade. Essas diferenças entre os clones de erva-mate podem estar relacionadas com diferença nos parâmetros cinéticos de absorção, como já elucidado em trabalhos com clones de eucalipto (LIMA et al. 2005, PINTO et al. 2011), ou com diferenças na exploração radicular do solo que é incipiente nos primeiros meses. Assim, é necessária uma maior concentração de nutrientes no solo para que a planta assimile quantidade suficiente para sua nutrição na fase inicial de desenvolvimento.

A exportação de $S$ pelas folhas, ECOM e total foram influenciadas pela dose de $S$ ao solo (Tabela 1; Figura 2). A quantidade de $S$ exportada teve comportamento inverso ao observado para a produção, provavelmente devido a um efeito de diluição do nutriente em um maior volume de massa na dose de $2,4 \mathrm{~kg}$ ha $^{-1}$ de $\mathrm{S}$. Neste sentido, enquanto o teor de $S$ no tecido vegetal teve redução de $70 \%$ em relação à testemunha (dados não apresentados) para a dose de maior resposta, a produção nesta mesma dose foi apenas $50 \%$ maior.

Já para a exportação de S pelo GG, houve resposta somente do clone, com maior exportação para o clone F2, com média de $0,52 \mathrm{~kg} \mathrm{ha}^{-1}$, ao passo que $\mathrm{F} 1$ exportou em média $0,16 \mathrm{~kg} \mathrm{ha}^{-1}$. A quantidade de $S$ exportada é pequena em virtude de a produtividade ser baixa, pois até os 24 meses de idade as plantas estão em fase inicial de crescimento, tendo sido realizada apenas uma colheita. Provavelmente em condições de baixa produtividade e exportação de $\mathrm{S}$, a produção pode ser sustentada apenas pela mineralização da matéria orgânica (TIECHER et al. 2012), contudo a resposta da erva-mate indica que deve-se ter cuidado com a adubação sulfatada para essa cultura.

No geral, a folha é o órgão da planta que mais exporta $S$, em relação aos galhos, seguindo a sequência $F O>G F>G G$. Assim, embora a fração $G G$ represente maior massa, a quantidade de $S$ exportada é a menor. Isso ocorre porque o GG tem menor teor de $S$ no tecido que as demais partes da planta avaliada. Cabe ressaltar que esses dados são apenas da primeira colheita, quando a produtividade ainda é pequena. No entanto, para ervais adultos bem nutridos com produtividade em torno de $30 \mathrm{Mg} \mathrm{ha}^{-1}$ (SANTIN et al. 2014), a exportação de S pela colheita deverá se intensificar, condição que poderá alterar a demanda do nutriente pela planta e, consequentemente, a necessidade de maior disponibilidade de $S$ no solo.

A adubação sulfatada aumentou o sulfato disponível no solo até valores de $14 \mathrm{mg} \mathrm{kg}^{-1}$ (dose de $3,6 \mathrm{~kg}$ $\mathrm{ha}^{-1}$ de S), apresentando resposta linear à aplicação de $\mathrm{S}$ ao solo (Figura 3). Para cada kg de $\mathrm{S}$ aplicado, os teores de $S$ no solo aumentaram em $1,9 \mathrm{mg} \mathrm{kg}^{-1}$. Pelos resultados de produção de massa verde, a melhor dose de $S$ foi de $1,56 \mathrm{~kg} \mathrm{ha}^{-1}$ de $\mathrm{S}$ e, ao substituir este valor na equação da Figura 3, chegaríamos a um teor no solo de $9,89 \mathrm{mg} \mathrm{kg}^{-1}$ de $\mathrm{S}$, indicando que o teor crítico de enxofre disponível no solo para a erva-mate é 
de $10 \mathrm{mg} \mathrm{kg}^{-1}$, e não 5,0 mg kg-1, como preconizado pela CQFS-RS/SC (2016). Dessa maneira, a erva-mate deveria ser reclassificada como uma espécie exigente em enxofre. Isso é confirmado, de maneira genérica, pela própria análise química inicial da área, pois apresentava um teor geral do local de $8,2 \mathrm{mg} \mathrm{dm}^{-3} \mathrm{de}$ enxofre disponível e, mesmo com este teor inicial, houve resposta das plantas às doses de enxofre estudadas.
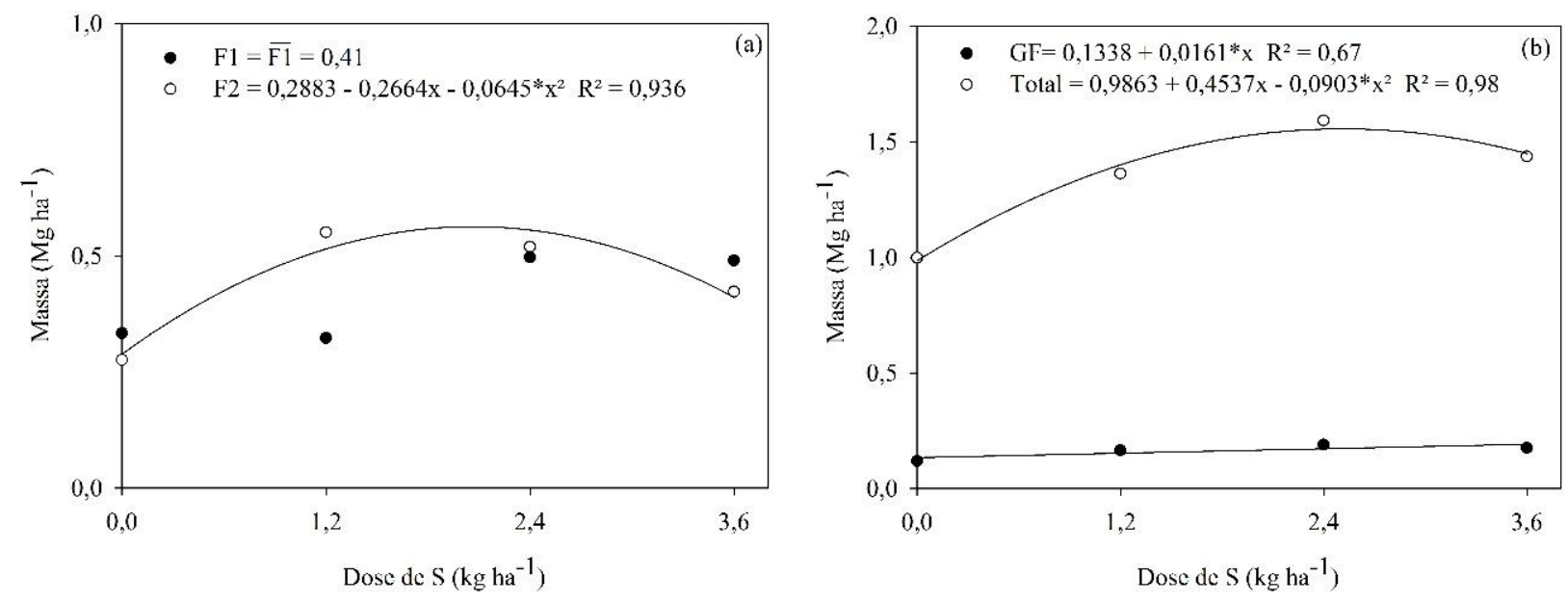

Figura 1. Massa verde de galho grosso GG (a), de galho fino (GF) e total (b) de clones de erva-mate (F1 e F2) submetidos à adubação com enxofre. *, significativo a $5 \%$ de probabilidade.

Figure 1. Thick twig (GG) mass (a) as a function of yerba mate clone and application of $S$ to the soil and; (b) thin twig mass (GF) and total mass of yerba mate submitted to sulphur fertilization. GG = thick twig; GF = thin twig; Total = total mass. F1 = F1 clone; F2 = clone F2.

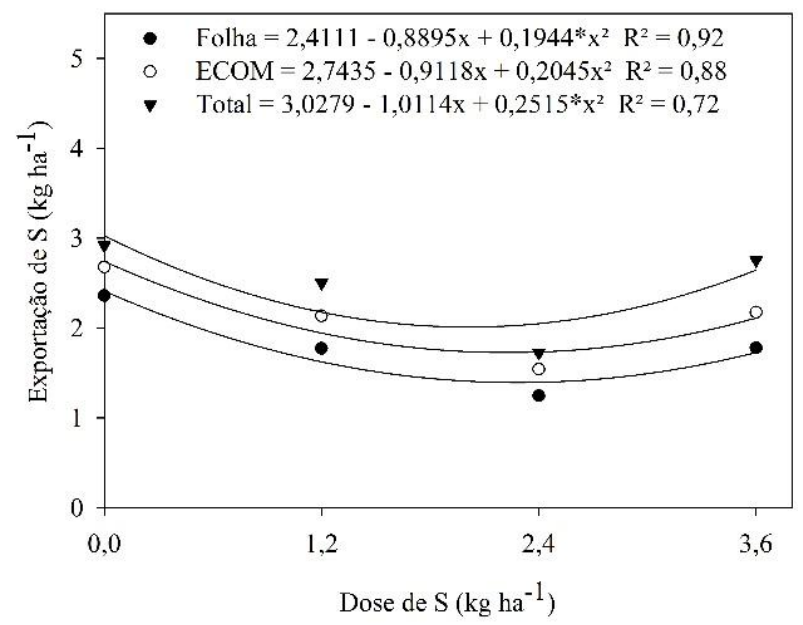

Figura 2. Quantidade de S exportada através da folha, ECOM e total após 24 meses de cultivo com ervamate em um Cambissolo Húmico. Folha = exportação de $S$ pela folha; $E C O M=$ parte comercial de erva-mate. Total $=\mathrm{GF}+\mathrm{GG}+\mathrm{FO}$.

Figure 2. Quantity of $S$ exported through the leaf, ECOM and total after 24 months of cultivation with Mate herb in a Humus Cambisol. Sheet $=S$ Export by Sheet; ECOM = commercial part of mate. Total = $G F+G G+F O$.

A resposta encontrada para enxofre alerta que os clones de erva-mate podem apresentar exigências nutricionais mais elevadas do que as estabelecidas para os ervais tradicionais, oriundos de matrizes sem seleção genética e multiplicados por via seminal. Apesar do rápido crescimento radicular e da maior eficiência nutricional de clones florestais selecionados por melhoramento genético (PINHEIRO et al. 2016), essas técnicas têm por objetivo o aumento da produção e consequentemente elevam a exportação de nutrientes. Desta maneira, a modernização do sistema de produção da cultura exigirá a revisão da resposta desses novos materiais genéticos a todos os nutrientes essenciais, demandando um esforço dos cientistas no sentido de estabelecer novos teores críticos dos nutrientes para a cultura. 


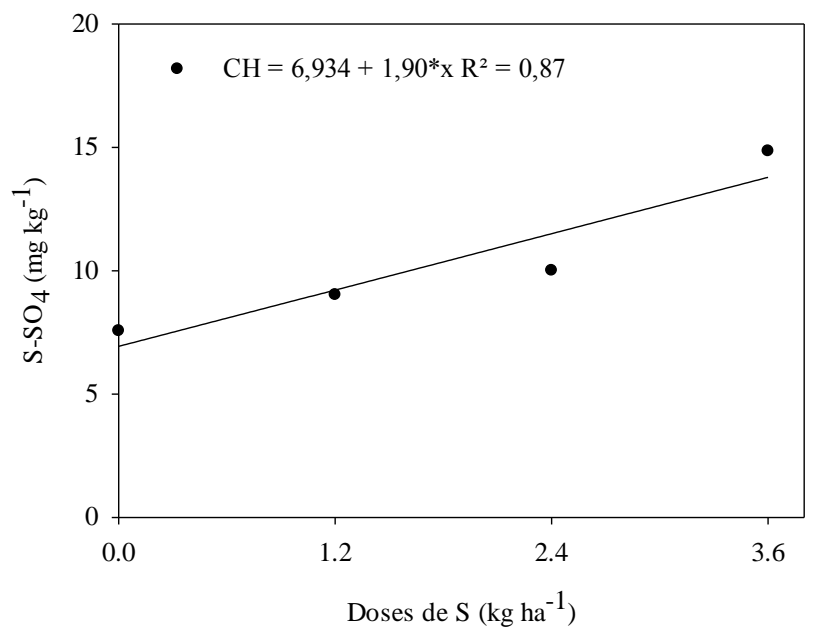

Figura 3. Teor de sulfato disponível no solo após 24 meses de cultivo de erva-mate em um Cambissolo Húmico.

Figure 3. Available sulphate in the soil after 24 months of cultivation of yerba mate in a Humic Cambisol.

\section{CONCLUSÃO}

A erva-mate responde à adubação sulfatada na fase de implantação do erval, independentemente do clone avaliado, exigindo teores mínimos de sulfato no solo de $10 \mathrm{mg} \mathrm{dm}^{-3}$.

\section{AGRADECIMENTOS}

Os autores agradecem ao CNPq pelo apoio e à Capes pela concessão da bolsa durante o período de pesquisa. Ao empresário Alfeu Schneider pela colaboração na realização deste experimento, ao Laboratório de Química e Fertilidade do solo UDESC/CAV, à Baldo S.A. de São Mateus do Sul, PR e à Embrapa Floresta de Colombo, PR, que, juntas, possibilitaram a realização deste trabalho.

\section{REFERÊNCIAS}

ALVAREZ VH et al. 2001. Métodos de análises de enxofre em solos e plantas. Viçosa: UFV. 131p.

ALVAREZ VH et al. 2007. Enxofre. In: NOVAIS RF et al. Fertilidade do solo. Viçosa: Sociedade Brasileira de Ciência do Solo. pp. 595-644.

BENIN CC et al. 2013. Enraizamento de miniestacas apicais, intermediárias e basais em clones de Eucalyptus benthamii. Floresta 43: 421-428.

Brun EJ et al. 2014. Implicações nutricionais da colheita de erva-mate: estudo de caso na região sudoeste do Paraná. Ecologia e Nutrição Florestal 1: 72-79.

CQFS-RS/SC. 2016. Comissão de Química e Fertilidade do Solo. Manual de calagem e adubação para os Estados do Rio Grande do Sul e de Santa Catarina. 11.ed. Sociedade Brasileira de Ciência do Solo - Núcleo Regional Sul. 376p.

EMBRAPA. 2013. Empresa Brasileira de Pesquisa Agropecuária. Sistema Brasileiro de Classificação de Solos. 3.ed. Brasília: Embrapa. 353p.

EPAGRI. 2002. Empresa de Pesquisa Agropecuária e Extensão Rural de Santa Catarina. Atlas climatológico do Estado de Santa Catarina. Florianópolis: Epagri. (CD-Rom).

FERREIRA DF. 2008. Sisvar: um programa para análises e ensino de estatística. Revista Científica Symposium 6: 3641.

KLIEMANN HJ \& MALAVOLTA E. 1993. Disponibilidade de enxofre em solos brasileiros. I. avaliação dos potenciais de mineralização de nitrogênio e enxofre por incubação aberta. Pesquisa Agropecuária Tropical 23: 129-144.

LIMA AMN et al. 2005. Cinética de absorção e eficiência nutricional de $\mathrm{K}^{+}, \mathrm{Ca}^{2+}$ e $\mathrm{Mg}^{2+}$ em plantas jovens de quatro clones de eucalipto. Revista Brasileira de Ciência do Solo 29: 903-909.

MELO LCA et al. 2011. Nutrição e produção de matéria seca de milho submetido a calagem e adubação sulfatada. Pesquisa Agropecuária Tropical 41: 193-199.

Oliva EV et al. 2014. Composição nutricional de procedências e progênies de erva-mate (Ilex paraguariensis St. Hil.) cultivadas em Latossolo Vermelho distrófico. Ciência Florestal 24: 793-805.

PINHEIRO RC et al. 2016. A fast exploration of very deep soil layers by Eucalyptus seedlings and clones in Brazil. Forest Ecology and Management 366: 143-152.

PINTO SIC et al. 2011. Eficiência nutricional de clones de eucalipto na fase de mudas cultivados em solução nutritiva. Revista Brasileira de Ciência do Solo 35: 523-534.

SANTIN D et al. 2008. Crescimento de mudas de erva-mate fertilizadas com N, P e K. Scientia Agraria 9: 59-66. 
SANTIN D et al. 2013a. Crescimento e nutrição de erva-mate influenciados pela adubação nitrogenada, fosfatada e potássica. Ciência Florestal 23: 363-375.

SANTIN D et al. 2014. Effect of potassium fertilization on yield and nutrition of yerba mate (llex paraguariensis). Revista Brasileira de Ciência do Solo 38: 1469-1477.

Santin D et al. 2013b. Nutrição e crescimento da erva-mate submetida à calagem. Ciência Florestal 23: 55-66.

SANTOS KA et al. 2004. Polifenóis em chá de erva-mate. Nutrição Brasil 3: 47-50.

TAIZ L et al. 2015. Plant Physiology and Development. 6.ed. EUA: Sinauer Associates. 761p.

TIECHER T et al. 2012. Forms of inorganic phosphorus in soil under different long term soil tillage systems and winter crops. Revista Brasileira de Ciência do Solo 36: 271-281.

XAVIER A et al. 2009. Silvicultura clonal: princípios e técnicas. 2.ed. Viçosa: UFV. 272p.

XAVIER A \& SILVA RL. 2010. Evolução da silvicultura clonal de Eucalyptus no Brasil. Agronomía Costarricense 34: 9398.

WENDLING I et al. 2007. Produção e sobrevivência de miniestacas e minicepas de erva-mate cultivadas em sistema semi-hidropônico. Pesquisa Agropecuária Brasileira 42: 289-292. 